ISSN: 0213-2079 - ISSN electrónico: 2386-3889

DOI: https://doi.org/10.14201/shhmo2020421255285

\title{
RECTORES DEL COLEGIO DE LA COMPAÑÍA DE JESÚS EN SALAMANCA: APROXIMACIÓN HISTÓRICA A UN DOMICILIO UNIVERSITARIO
}

\section{Rectors of the college of the Society of Jesus in Salamanca: historical aproximation to an universitarian residence}

\section{Cristo José DE LEÓN PERERA ${ }^{1}$}

GIR «Historia Cultural y Universidades Alfonso IX», Instituto de Estudios Medievales y Renacentistas y humanidades digitales-Universidad de Salamanca deleper@usal.es

Fecha de recepción: 10/03/2019

Fecha de aceptación: 12/11/2019

RESUMEN: La figura de rector es la más importante en todas las instituciones. En los colegios de la Compañía de Jesús observamos una plasmación de esta tendencia. Lo que pretendemos es presentar una élite intelectual salmantina y sus diferentes procesos de búsqueda y proyección.

Palabras clave: Universidad de Salamanca; rector; jesuita; colegio; gobierno.

ABSTRACT: The figure of the Rector is the most important in any institution. In the college of the Society of Jesus we observe the reflection of this tendency. We intend to present an intelectual elite in Salamanca and its different research processes and their impact.

Keywords: University of Salamanca; rector; jesuit; college; government.

1. https://orcid.org/0255-2853-1647-1424

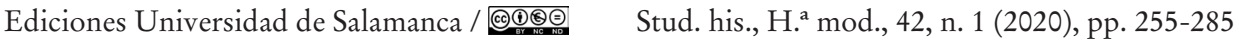


CRISTO JOSÉ DE LEÓN PERERA

RECTORES DEL COLEGIO DE LA COMPAÑÍA DE JESÚS EN SALAMANCA: APROXIMACIÓN HISTÓRICA A UN DOMICILIO UNIVERSITARIO

\section{INTRODUCCIÓN}

La intención de la presente investigación no es la de presentar una historia del colegio de la Compañía de Jesús en Salamanca en su periodo antiguo (1548-1767), sino dar a conocer, cronológicamente, los principales rasgos característicos de la figura rectoral de dicho colegio como cabeza y representación de la institución. Quiénes eran, de dónde provenían, cuáles eran sus funciones, qué papel ejercieron en el conjunto del gremio universitario o incluso en la ciudad,... son algunas de las preguntas que se muestran sin resolver.

Hasta el presente, nada se sabe -salvo excepciones biográficas puntuales (cfr. De León, 2020: 148-167)- de los setenta y seis períodos rectorales que transcurrieron durante los doscientos diecinueve años de existencia del domicilio colegial con anterioridad al extrañamiento de Carlos III. La mayoría de estos rectores ha ocupado cargos importantes a nivel de la Provincia jesuítica de Castilla, así como de la Asistencia de España e, incluso, internacional.

Esto hace que los jesuitas charros, y aún más concretamente aquellos que ocuparon el oficio de rector en este colegio, poseyesen un estatus notable en la propia ciudad de Salamanca y, cómo no, en el gremio y Claustro de la Universidad. El domicilio de la Compañía se convirtió en uno de los centros formativos vinculados al Alma Mater con mayor internacionalidad y, como consecuencia de esto, su rector poseyó una proyección considerable.

Para poder situar esta figura en el tiempo debemos indicar que la creación del colegio de Salamanca se remonta al 9 de febrero de $1548^{2}$, siendo obispo de Salamanca Pedro de Castro ${ }^{3}$, cuando se culminan los deseos ignacianos de abrir un domicilio a la sombra de la Universidad de la Corona ${ }^{4}$. Esto fue realizado gracias a

2. En Archivum Historicum Societatis Iesu (ARSI). Collegia 303. Sig. 1588. No4, fol. 1r. «Initio hujus anni 1548, scilicet nona februarii, pater Michaël de Torres, sacrae Theologiae doctor, expensis cardinalis de Coria, domini Francisci de Mendoza, cum socio ipsi adjuncto a Francisco de Villanova, Salmanticam se contulit». Vita Ignatii Loiolae et rerum Societatis Iesu bistoria (Chron). I, p. 297. En la carta de Miguel de Torres al padre Antonio Araoz firmada en Salamanca el 24 de abril de 1548 [Monumenta Historica Societatis Iesu (MHSI). Epistolae mixtae ex variis Europae locis (Epp. Mixtae). I, p. 491] tampoco deja duda de la fecha; por tanto, no sabemos -ya que no indica la fuente- por qué el padre Rodríguez (1966: 104; Cfr. Hernández, 1987: 724.) adelantó un mes la llegada.

3. «[Pedro de Castro] fue vno de los mayores y más doctos prelados que en aquel tiempo tuuo la Iglesia de España. En el año segundo de su prelancia, don Francisco de Mendoça, cardenal de Roma y obispo de Coria, fundó en Salamanca el colegio de la Compañía de Iesvs, de reigiosos del mismo orden» (González, 1606: 488).

4. «Historia del collegio de Salamanca, sacada de lo que el padre Miguel Marcos, poco antes de su muerte, recogió de los papeles y annales de este collegio y de lo que él testificó como testigo de vista, después de que el Benerable padre Ignacio de Loaysa [sic.], fundador y padre primero de la Compañía de Jesús, inpetro de la Sede Appostólica, beneplácito y confirmación

Ediciones Universidad de Salamanca / 요 Stud. his., H. ${ }^{a}$ mod., 42, n. 1 (2020), pp. 255-285 
CRISTO JOSÉ DE LEÓN PERERA

RECTORES DEL COLEGIO DE LA COMPAÑÍA DE JESÚS EN SALAMANCA: APROXIMACIÓN HISTÓRICA A UN DOMICILIO UNIVERSITARIO

las promesas de Francisco de Mendoza que, aunque no se cumplieron con el transcurso del tiempo, sirvieron para culminar los intentos que venían dándose desde junio de $1545^{5}$. Posteriormente, mediante mandas testamentarias, doña Margarita de Austria ratificará la fundación convirtiendo el domicilio formativo en Colegio Real, dotándolo notablemente y favoreciendo su sustento ${ }^{6}$.

Por tanto, gracias a una mujer se les otorgará a los jesuitas salmantinos un impacto de magnitud, con carácter de núcleo, que podría ser reflejo de las nada baladí disputas teológicas internacionales (cfr. De León, 2018c: 281-294). Hacemos referencia al vivero de toda la Provincia de Castilla, e incluso de la Asistencia de España, que se mostraba como lugar de paso obligatorio para los teólogos. Por lo cual, hace que este estudio sea imprescindible para poder poseer uno de los numerosos tintes que colorearon la Salamanca universitaria de la Edad Moderna y, más concretamente, la documentación custodiada en su biblioteca histórica.

Por muy extraño que parezca, poco más que lo señalado se conoce del domicilio de la Compañía de Jesús en Salamanca (cfr. De León, 2018a: 387-397). Este colegio vinculado a la Universidad de Salamanca ha quedado olvidado por la historiografía que, desde el siglo XIX, viene analizando internacionalmente las casas de la orden con similar importancia a la de la urbe del Tormes.

En otro lugar (2018b: 18) hemos señalado que los jesuitas formaban uno de los grupos intelectuales más prestigiosos que ha existido en la historia de la Universidad de Salamanca, o al menos de uno de los que han llevado su nombre más allá de las fronteras de la Corona Hispana. Lo que pretendemos con este artículo es presentar diversos modelos paradigmáticos que ejemplifican la totalidad de los casos sobre la figura de aquel que presidía al conjunto de la orden en Salamanca.

de su instituto, movido con aquel su gran celo, deseó asentar su religión en la Universidad de Salamanca. Dos cosas principalmente encendía en su pecho este deseo, la memoria de las persecuciones, que por el servicio de Dios nuestro Señor avía en ella padescido, a las quales quería responder con servicios y beneficios, en la más alta manera que pudiese, y en el conocer de quanto augmento podía ser a su religión y de quanto fructo en las almas el darse a conocer y exercitar la Compañía sus ministerios en el más noble y frequentado seminario que entonces tenía la nobleça y juventud christiana por que en esto, los árboles tiernos y pequeños, son transplantados con mayor fructo y enxertos con grandes ventajas. Dos cosas impedían la execución desta voluntad: una la falta de persona que, a satisfación suya, tuviese los talentos y caudal necesarios para emprender una cossa de tanto momento, con esperanças de hollar sobre las dificultades que se le opusiesen; y otra, la de el arrimo de algún príncipe a cuya sombra y con cuyo favor se zanjase y prosiguiese este nuevo collegio y obra de Dios faltas necessarias por ser tan recién nascida la Compañía que ni podía bien averse dado a conocer, ni tenía hedad para aver concebido y criado a sus pechos muchos hijos tales como semejantes empresas requerían». ARSI. Provincia Castellana 35.I, fol. 131r.

5. MHSI. Epp. Mixtae. I, pp. 223-230.

6. Cfr. Archivo Histórico Nacional de España (AHN). Leg. 831, 1-2.

Ediciones Universidad de Salamanca / అ@@ Stud. his., H. ${ }^{a}$ mod., 42, n. 1 (2020), pp. 255-285 


\section{LA FIGURA RECTORAL EN EL CUERPO LEGISLATIVO DE LA COMPAÑIIA DE JESÚS: CARACTERÍSTICAS ESENCIALES}

Una vez que han sido planteadas las premisas fundamentales sobre el colegio jesuítico del territorio salmantino, hacemos referencia a su aspecto gubernamental y más concretamente a su directiva. El trato ignaciano -y de sus primeros compañeros- con las universidades de Alcalá, Salamanca y París, así como con sus redes colegiales, dejó huella en la organización interna y el régimen de administración del domicilio colegial.

Esta idea, defendida por todos los estudiosos, es profundizada en pocos casos. Ignacio fue un alumno atípico para el periodo; realizó sus cursos académicos a una edad avanzada y esto le facilitó una visión analítica de su entorno académico. De estas reflexiones personales se extrajo la normativa interna, así como el carisma y su importancia.

En lo respectivo a los colegios, en las Constituciones, sobre todo en su cuarta parte, quedó reflejada toda su normativa. Observamos un intento de equilibrar los poderes, pero siempre sometidos en obediencia a la figura del rector; una estructuración en organismos colegiados -como es el caso de la consulta- y cargos unipersonales. Estamos ante la propuesta de reforma eclesiástica ignaciana para solventar las necesidades que estaban originando las diversas renovaciones del cristianismo y lograr así la transformación demandada.

El padre rector representa la cabeza del modelo ignaciano de estructuración colegial, es decir, corresponde al superior. En él se deposita todo el poder, lo cual será razón por la que se le exigen grandes cualidades en los ámbitos personal, espiritual y académico.

Se trata de un oficio que tiene por yugo la carga de todos los derechos y obligaciones derivados de la representación local de la orden, puesto reconocido por toda la urbe y de autoridad destacada. A su vez, en lo que corresponde a la Provincia, Salamanca ostentaba un lugar privilegiado: su rector, en aquellos casos que no era padre provincial, era visitador o consultor.

Buscando el influjo del Tormes en la Compañía de Jesús debemos señalar que sabemos que los rectores del Estudio salmantino de este período eran electos democráticamente mediante el voto estudiantil y su oficio transcurría durante un año, de San Martín a San Martín. Esta esencia de la Universidad no fue mantenida en la organización internacional de la orden puesto que, en primer lugar, eran nombrados por el padre general o por su representante, es decir, el padre provincial o aquel a quien el prepósito de Roma le concediese tal autoridad ${ }^{7}$. A ellos, en la figura del

\section{Constituciones, 490 .}


provincial, debían dar cuenta de la labor que realizaba durante las visitas al colegio o en las cartas destinadas a Roma. De igual manera, su encargo era trienal y no anual.

En este aspecto y tras observar que Salamanca no fue el paradigma tomado por Ignacio debemos buscar de dónde recibe tal influencia. Según Echarte (2001: 1750), el título de rector sería recibido del ámbito colegial italiano más que del parisino, en el que era más propia la figuración de la cabeza bajo el nombre de maestro o principal.

Fuera cual fuese su modelo, lo cierto es que el rector debía ser una persona seleccionada cuidadosamente. Cualquiera no era válido para ostentar este cargo y la orden fue consciente de esto en todo momento.

En las Constituciones se realiza una minuciosa descripción de las características que debe ostentar el jesuita para que se muestre como idóneo:

El rector se procure que sea de mucho exenplo y edificación y mortificación de todas inclinaciones siniestras, specialmente probado en la obediencia y bumildad; que sea ansimesmo discreto y apto para el gobierno y tenga uso de las cosas agibles y speriencia en las spirituales; que sepa mezclar la severidad a sus tiempos con la benignidad; sea cuidadoso, sufridor de trabajo y persona de letras, y finalmente de quien se puedan confiar y a quien puedan comunicar seguramente su auctoridad los prepósitos superiores; pues quando maior será ésta, mejor se podrán gobernar los colegios a mayor Gloria Divina ${ }^{8}$.

Desde su elección, el padre rector se convertía en el representante local de una orden internacional con la influencia de la Compañía de Jesús. El prestigio (o su contrario) de cada territorio dependía en última estancia de la imagen aportada por la comunidad que en él vivía bajo la responsabilidad, potestad y autoridad de un rector que velase por el cumplimiento de las Constituciones, así como que lograse una conducta intachable en nombre de la Curia General.

No nos situamos ante una figura baladí. Cada caso, estudiado minuciosamente, poseía diversas normativas especiales debido a su responsabilidad. A partir de 1561 contaría con 17 reglas que Laínez mandaría a imprimir bajo el título de Officium rectoris, revisadas por la II Congregación General, siguiendo el mandato de Francisco de Borja y ampliadas por Mercuriano (1580) y Acquaviva (1582). Se buscaba la persona ajustada para el oficio que consistía en hacer guardar las Constituciones, procurar el aprovechamiento de los habitantes del colegio en virtudes y letras, así como conservar su salud y bienes muebles 9 . Esta persona debía ser, como norma general, coadjutor temporal ${ }^{10}$; a pesar de esto, el propio Ignacio llegó a nombrar a algún profeso e incluso novicios para este cargo (cfr. Vila, 2010: 126-127), situación

\footnotetext{
8. Constituciones, 423

9. Constituciones, 424.

10. Constituciones, 421.
}

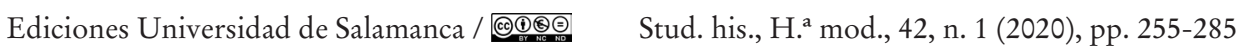


que en el contexto salmantino nunca se dio puesto que la «nobleza de las letras» siempre influyó en la vida de este domicilio.

Con todo lo que ha sido señalado ha podido advertirse que el rector jesuita o al menos su simbología recibió en cada territorio importancia más que notable. En ciudades con más de un domicilio -caso de Valladolid (cfr. Burrieza, 2000: 139-162)se diluía tal influjo recayendo casi en su totalidad en la casa matriz o sede, tanto gubernamental como intelectual.

Salamanca tuvo tan solo una casa de la Compañía, aunque sus jesuitas, en momentos puntuales, se encontrasen viviendo fuera de ella pero siempre dentro de los muros de la urbe para poder realizar su apostolado. Debe ser entendida como una idea de comunidad y no como patrimonio inmueble para que no seamos llevados a equivocación. Por tanto, con anterioridad a la Fundación Regia, así como con posterioridad, tan sólo será una comunidad y por ende un único rector su cabeza.

\section{LA BÚSQUEDA Y ELECCIÓN DEL PRIMER RECTOR}

Una vez planteada la repercusión de la figura rectoral queremos que esas ideas impersonales tomen consonancia biográfica que respalde lo expuesto. Comenzaremos con el primer rector del colegio de Salamanca puesto que nos parece lo adecuado. Este primer rector fue, en nombre del mismo Ignacio, el fundador de Salamanca.

Para contextualizar oportunamente el nombramiento del iniciador del domicilio salmantino debemos retroceder a los primeros intentos fundacionales del colegio charro a pesar de ser anteriores al proyecto de Francisco de Mendoza, concretamente al viaje realizado por Antonio Araoz desde Portugal hacia Valladolid: «[...] en Salamanca allamos mucha gente muy dispuesta, y deseosa de la Compañía, prediqué solo una vez. De muchos fuy rogado para que allí quedase, o a lo menos tornase presto» ${ }^{11}$.

Aunque su estancia no se dilató en el tiempo, reflejaba la existencia en la ciudad de personas dispuestas y deseosas del carisma ignaciano; el modelo planteado serviría como un novedoso contrapeso al escolasticismo -tan defendido en la urbe- cautivando la atención, incluso, de diversos doctores universitarios ${ }^{12}$.

Antes de continuar queremos hacer mayor hincapié en esta cuestión. La figura del padre Araoz y el trato recibido por los salmantinos en esta visita muestran la

11. MHSI. Epp. Mixtae, I, pp. 202-204.

12. «Cum Salmantica transirent, ibi concionatus est pater Araoz, et tam multa spiritualia negotia se offerebant, ut parum abfuerit quin ibi quod reliquum erat Quadragesimae exigerent. Inviserunt primarios Universitatis doctores, qui magna cum benevolentia operam suam Societati offerebant, et inter caeteros fray Alphonsus de Castro et fray Franciscus de Victoria». Chron. I, p. 160.

Ediciones Universidad de Salamanca / @@ Stud. his., H. ${ }^{a}$ mod., 42, n. 1 (2020), pp. 255-285 
CRISTO JOSÉ DE LEÓN PERERA

RECTORES DEL COLEGIO DE LA COMPAÑÍA DE JESÚS EN SALAMANCA: APROXIMACIÓN HISTÓRICA A UN DOMICILIO UNIVERSITARIO

simbología que rodeaba a los representantes de la Compañía de Jesús por parte de las élites intelectuales. A pesar de esto, no debemos dejar de señalar que Araoz había realizado estudios en Salamanca y por tanto era reconocido por el gremio, lo cual favoreció notablemente las futuras relaciones entre los representantes de ambas instituciones.

En junio de 1545, Araoz volverá a realizar tal petición al propio Ignacio. A su vez, señala que el padre Fabro también se había acercado a la ciudad universitaria y había realizado en ella diversas labores apostólicas y evangelizadoras. De estos ministerios salieron varias propuestas para realizar la fundación a orillas del Tormes. Entre ellas deben destacarse la de un estudiante ${ }^{13}$ y la de Antonio de Córdoba, obispo de Salamanca ${ }^{14}$.

Dejando a un lado la consciente omisión de estas ofertas en las crónicas oficiales de la orden ${ }^{15}$, así como en las investigaciones realizadas en el pasado siglo, continuemos con la carta escrita por el padre Andrés de Oviedo el 20 de febrero de 1547 desde el colegio de Gandía. En ella el padre Oviedo advertía la mejoría del duque tras ejecutársele diversas sangrías y se dan noticias de la estancia del padre Torres en Zaragoza. Torres, según señala Andrés de Oviedo, mantenía ciertas dudas sobre si continuar en esta ciudad o partir hacia Sevilla y sus múltiples posibilidades transoceánicas.

A su vez, se deja noticia de que, en Gandía, se están preparando sujetos para ser enviados a Salamanca; sujetos que doña Juana de Meneses quería que realizasen su apostolado en Alcalá ${ }^{16}$. Miguel de Torres se encontraba discerniendo posibilidades.

13. «Vn estudiante, hijo de vn conde que conosçimos en Salamanca, ha venido a vernos [a Valladolid]. Es vuelto con yntençión de procurar cómo algunos estudiantes nuestros tengan cómo estudiar en Salamanca». MHSI. Epp. Mixtae. I, p. 225.

14. «El obispo de Salamanca, y el obispo de Lugo nos aman, y dezíame que muy bien le paresçia lo de los colegios». MHSI. Epp. Mixtae. I, p. 228.

15. Posiblemente sea consecuencia de la necesidad de crear la propia historia fundamentándose en la memoria, llegándose a mitificarla en diversos casos (cfr. O’Malley, 2016: X).

16. «Pensando que su señoría [Francisco de Borja], como él me dizie, escreviria presto, yo he sido negligente en rresponder, y así, dexando lo más largo para quando su señoría escriba, por esta cumpliré con lo que me manda nuestro padre, el liçençiado Araoz: es a saber, sobre los dos estudiantes que la señora doña Juana de Meneses quiríe prouar para la Compañía en Alcalá, aviéndole parecido al padre liçençiado que seríe mayor seruicio del Señor, que estos tales estuviesen en Salamanca, si la señora doña Juana era así contenta, y pareçiendo a su reverencia que seríe al propósito que fuese el vno Isydoro [Bellini], el qual está aquí, que vino de Portugal; y por no saber si vuestra paternidad le embió a llamar, que yo escriviese, avisando desto a vuestra paternidad, y viendo que la señora doña Juana determinaba con la venida de Isydoro, mucho en el Señor nos somos alegrado. Y yo hablé con la señora doña Juana de inviarle a Salamanca con otros, la qual penitus es contenta que sea como la Compañía lo ordenare, que creo combidará a todos a amar en Christo nuestro Señor a esta señora, ver la liberalidad con que lo otorgó y por el grande amor que tiene a la Compañía. Y después llevé a ver al señor duque a Isydoro.

Ediciones Universidad de Salamanca / @®@@ Stud. his., H. ${ }^{a}$ mod., 42, n. 1 (2020), pp. 255-285 
CRISTO JOSÉ DE LEÓN PERERA

RECTORES DEL COLEGIO DE LA COMPAÑÍA DE JESÚS EN SALAMANCA: APROXIMACIÓN HISTÓRICA A UN DOMICILIO UNIVERSITARIO

La América Hispánica no dejaba de ser un destino apetecible en lo que respecta al celo evangelizador. Salamanca, como ciudad universitaria, no quedaba atrás; en ella se podía entrar en contacto con toda la futura red de burócratas del Reino. Dos opciones señaladas en un mismo domicilio y que, indudablemente, comenzaban a indicar a un mismo grupo de jesuitas como posibilidad.

El primer jesuita destinado a Salamanca fue Isidoro Bellini. Pero he aquí una de las dificultades iniciales: Ignacio de Loyola quería a Bellini para Roma por su gran edificación y ejemplaridad. Se encontraban ante un hombre de probadas letras y virtudes. Francisco de Borja tendría puesto en él otro destino: Salamanca.

Ignacio y Borja señalaban distintos caminos, pero en toda la correspondencia epistolar destinada a la Asistencia de España no ofrece duda alguna de la alta estima que tenía el padre general a recomendaciones que realizaba el grande de España. En carta al padre Araoz del 18 de mayo de 1547 recibirán la respuesta desde Roma a esta situación; se cumplirán los deseos del duque ${ }^{17}$.

Estamos ante la primera ocasión en que a un miembro de la Compañía de Jesús se le otorga como destino Salamanca, territorio que hasta este momento no había quedado señalado como lugar en el que debía realizarse de forma inmediata apostolado. El encargo se comenzaba a dilatar en el tiempo, el 10 de mayo de 1547, Antonio Araoz dirá que «[...] Hércules ${ }^{18}$ y Sbrando [sic.], o alias Isidoro, están en Gandía sperando lo que vuestra reverencia mandará, porque la señora doña Juana de Meneses quiere proveer dos en Salamanca, y parescen estos muy a propósito» ${ }^{19}$.

Andrés de Oviedo, desde Valencia, diez días después, señala:

[...] y también esperamos respuesta sobre Isidoro, que emos escrito a vuestra paternidad cómo le embió aqui el padre liçençiado Araoz, deseando que fuesen algunos estudiantes de los nuestros en Salamanca, en lugar de dos que la señora doña Juana de Meneses quería proneer en Alcalá, y que fuese Isidoro vno dellos, después que supiésemos si vuestra paternidad le avíe embiado particularmente a llamar a Isidoro

Y teniendo nuestros hermanos conclusiones (las quales tienen todos los domingos) delante del señor duque, que arguyó, y argumentando en ellas Isydoro, quedó su señoría y los demás muy satisfechos dél, y también de cómo se aprouechan los nuestros. Y así le parecíe al señor duque y a maestro Saboya, que era muy conueniente para yr a Salamanca, por la edificación. Así que, estando aquí, mientras sabemos la voluntad de vuestra paternidad, podrá avisarnos, si quiere que vaya a Roma Isydoro, o a Salamanca, como desea el padre licenciado» (MHSI. Epp. Mixtae. I, p. 338). Sobre esto, Andrés de Oviedo vuelve a tratar en la epístola enviada el 24 de febrero de 1547 (MHSI. Epp. Mixtae. I, p. 341).

17. «Isbrando [sic.] a Salamanca, como paresce al duque». MHSI. Sancti Ignatii de Loyola Societatis Iesu fundatoris epistolae et instructiones (Epp. Ign). I, p. 512. No hay duda de que está haciendo referencia a Isidoro Bellino ya que su apodo era Sbrando.

18. Había sido destinado por confesor a Zaragoza, cfr. MHSI. Epp. Ign. I, p. 512.

19. MHSI. Epp. Mixtae. I, p. 346.

Ediciones Universidad de Salamanca / అ@@ Stud. his., H. ${ }^{a}$ mod., 42, n. 1 (2020), pp. 255-285 
CRISTO JOSÉ DE LEÓN PERERA

RECTORES DEL COLEGIO DE LA COMPAÑÍA DE JESÚS EN SALAMANCA: APROXIMACIÓN HISTÓRICA A UN DOMICILIO UNIVERSITARIO

o no. Y si le pareçiere que devie de yr a Roma, quiénes yrán a Salamanca nos podrá vuestra paternidad avisar; que asi me lo a escrito nuestro padre el liçençiado, que yo escriviese a vuestra paternidad sobre esto, y por duplicadas, siendo contenta dello la señora doña Juana; la qual es contenta, y buelga que sea uno Isidoro, estando contenta de su edificación ${ }^{20}$.

Se refleja una serie de negociaciones alargadas en el tiempo más de lo deseado posiblemente por diversos factores (cruce epistolar y la tardanza propia de la época en ser recibidas y respondidas; $u$ otro tipo de causa como puede ser los hurtos de los que se queja Ignacio a Antonio Araoz en el mes de abril de $1547^{21}$ ). Lo cierto es que, desde Valencia, Andrés de Oviedo le dirá al padre general lo siguiente:

[...] y esto mismo tengo escrito antes a vuestra paternidad, y también cómo está Isidoro en Valençia hasta saber el pareçer de vuestra paternidad, si querrá que con otro vaya a estudiar a Salamanca, pareçiéndole al padre liçençiado que seríe muy bueno si la señora doña Juana de Meneses era contenta, que los dos estudiantes de la Compañia que su merced quiríe proueer en Alcalá, fuese en Salamanca, y siendo desto muy contenta, y que Isidoro valla estando edificados dél, se a detenido ${ }^{22}$.

Por no encontrar un compañero que cumpliese las expectativas necesarias para asistir a la Academia salmantina, en medio de una apertura misional que se extendía por todo el Reino, decidirán que Isidoro Bellino vaya definitivamente a Alcalá, tal y como en un principio, deseaba la benefactora Juana de Meneses ${ }^{23}$. Pero el padre general no había dado su parecer respecto a este cambio de destino por lo que, desde Gandía, se le solicitará premura en la respuesta ${ }^{24}$. Comenzaba a evidenciarse que el destino salmantino podía quedar frustrado.

20. MHSI. Epp. Mixtae. I, p. 349s.

21. «Las cartas que me escribistes me ymbiábades con el camarero del Papa, a las quales os remitíades, no han llegado a mis manos». MHSI. Epp. Ign. I, pp. 483s. A pesar de esto, debemos recordar que Ignacio destinaba a Salamanca a Isidoro el 18 de mayo de 1547 (cfr. MHSI. Epp. Ign. I, p. 512).

22. MHSI. Epp. Mixtae. I, p. 354.

23. «En lo que se avíe escrito de Salamanca, que fuesen dos estudiantes de los nuestros, los que la señora doña Juana de Meneses queríe proueer en Alcalá, siendo dello contenta, para lo qual pareçíe al padre liçençiado venir bien que fuese Isidro uno, siendo vuestra paternidad dello contento, y sabiendo su respuesta con cuidado, y está en Valencia; hales parecido que por no aver al presente subiecto alguno que convendríe para Salamanca, que fuesen en Alcalá estos estudiantes que la señora doña Juana quiere proueer: y que podrán ser Isidro y un maestro que allí han recebido, y que espere Isidro hasta saber la respuesta de vuestra paternidad». MHSI. Epp. Mixtae. I, p. 363.

24. Carta de Andrés de Oviedo fechada el 7 de mayo de 1547: «[...] mucho deseamos ver cartas de vuestra reverencia, por saber lo que se a de hazer de Isidro, si yríe a Salamanca o

Ediciones Universidad de Salamanca / 요 Stud. his., H. ${ }^{a}$ mod., 42, n. 1 (2020), pp. 255-285 
CRISTO JOSÉ DE LEÓN PERERA

RECTORES DEL COLEGIO DE LA COMPAÑÍA DE JESÚS EN SALAMANCA: APROXIMACIÓN HISTÓRICA A UN DOMICILIO UNIVERSITARIO

Mientras se esperaba respuesta desde Roma y por si se decidía no frustrar el intento salmantino, como compañero para Bellino, se planteaban a Milian o Estrada $^{25}$. La suerte corrida por ambos marcaría profundamente la llegada a Salamanca $^{26}$. Araoz estaba convencido de que a la ciudad del Tormes debía enviarse a un jesuita que tuviese ciertas «armas», es decir, que conociera perfectamente el instituto y en él llevase tiempo andado. Ni siquiera se había llegado a plantear la posibilidad de enviar a dichas tierras a un aprendiz. Sabían que estaban ante una plaza con ciertas dificultades y el sujeto que se enfrentase a ellas debía saber cómo hacerlo. En Salamanca se encontraba una élite intelectual ante la cual no debían mostrar debilidad alguna. Por estas razones, dejar a un lado el tema salmantino era algo que Araoz había meditado profundamente:

[...] puedo dezir a vuertra reverencia, y así lo digo, que por ventura en cosa no $e$ tenido más miramiento días a, que en esto; asy por desear que algunos entrasen en Salamanca, como, y más principalmente, porque no vbiese nota de mutabilidad, deseando más tardar en determinar, que, por seer fácil en ello, mudar de propósito: por que, si sapientis est mutare consilium, no menos es así eligir, que no convenga mudar, avnque esto es difícil en esta perefrinación. Quánto más que, padre mío, todo se hizo por expreso parescer del señor dottor Torres, que es arta paz para mí, porque se será contentamiento para vuestra reverencia ${ }^{27}$.

a Alcalá». MHSI. Epp. Mixtae. I, p. 370s. A finales de dicho mes seguían en la misma situación (cfr. MHSI. Epp. Mixtae. I, pp. 383-386).

25. Francisco de Estrada había sido paje del cardenal Gian Pietro Carafa. Tras ser despedido en 1538 como el resto de los españoles, se dirigió a Nápoles, donde se produjo su encuentro con Ignacio de Loyola que volvía de Montecasino tras ejercitar a Pedro Ortiz. Se encaminó con Ignacio a Roma donde realizó los Ejercicios Espirituales. En 1542 fue enviado a París para estudiar, pero, a consecuencia de la guerra entre Carlos I de España y Francisco I de Francia partió a continuarlos en Lovaina. Debe señalarse que, en numerosas epístolas, está localizado en la Corte, evidenciándose su reconocida calidad en el Reino. Lamentablemente para Milian no hemos podido recuperar los datos suficientes como para presentarlos con cierta coherencia.

26. "Quanto a lo que vuestra reverencia dize del mudar la provisión que daba doña Juana para Salamanca, atento lo que pasó, spero en nuestro Señor que se tubieron tales medios, que no abrá avido nota de liviandad en ello, avnque, como vuestra reverencia dize, no a faltado ocasión. De parte de doña Juana siempre vbo indiferencia, syn más inclinarse a vna parte que a otra, en todo rremitiéndose a nuestro parescer. Y para lo de Salamanca, siempre fue condicional, sperando que o Milian, que está en gloria, sanara, o Strada viniera: cesando qualquiera destas cosas, podía cesar la determinaión, sin que notasen mutabilidad. Y porque se rescibieron algunos al parescer aptos para estar en compañía de los más prouectos, que para ymbiarlos a Salamanca, por no estar tan versados en las cosas de la Compañía, no eran a propósito, y porque la charidad y limosna de doña Juana, asta aver tales, no dexase de obrar, su mismo confesor aplicó en el ínterin la provisión para aquellos nuevamente resciuidos en Alcalá». MHSI. Epp. Mixtae. I, pp. 390s.

27. MHSI. Epp. Mixtae. I, p. 391.

Ediciones Universidad de Salamanca / 요 Stud. his., H. ${ }^{a}$ mod., 42, n. 1 (2020), pp. 255-285 
Con estas evidencias, no tenemos -ni tampoco podríamos tener-duda alguna sobre la existencia de deseos de establecimiento en la ciudad de Salamanca, no sólo por una parte de la ciudad sino también por el mismo instituto. El propio Ignacio da cuenta de otro ejemplo de los referidos deseos en la epístola que le manda al padre Francisco de Villanueva ${ }^{28}$; escrito redactado entre los meses de agosto y septiembre de 1547 y según el cual, desde aproximadamente julio, el ya mencionado don Francisco de Mendoza, se encontraba animado, aparentemente mucho más que Ignacio, en realizar un colegio de la orden en Salamanca.

Esto es sabido porque el mismo iniciador de la orden da cuentas de la conversación mantenida. El prelado estaba dispuesto a costear con todos los gastos ocasionados por la fábrica y necesidades de los miembros del domicilio salmantino, recordaba la importancia de la Universidad y se lamentaba de fundaciones en otras urbes con menor relevancia. Lo cierto es que no se menciona el intento el fallido que hemos descrito con anterioridad. Tal vez aprovechan la situación y no evidencian que se tenían las miras puestas en la Academia salmantina para así favorecer la difícil y compleja financiación. Se trata de una verdadera muestra de la reserva mental tan característica de la Compañía de Jesús.

La actitud tomada por Ignacio de Loyola es fría y distante; todo lo contrario a la del obispo de Coria ${ }^{29}$. Con inseguridades o no por parte del fundador de la orden, lo cierto es que le ofrece a don Francisco de Mendoza enviar al padre Torres a Salamanca y el prelado acepta, culminándose así el largo proceso de elección de su primer rector ${ }^{30}$.

28. MHSI. Epp. Ign. I, 580-581.

29. En la carta se observa claramente la postura de Ignacio de Loyola que se muestra no del todo favorable a la llegada de forma estable por parte de miembros de la orden a Salamanca. En un primer lugar indica la falta de ministros y tras su insistencia decide nombrarle al padre Torres, pero indicándole que primero debe fundar en Zaragoza. Tal y como hemos señalado, esta actitud del padre general podría deberse a favorecer la insistencia -y por consiguiente fundamentación económica- por parde el prelado. Esto contrasta con la idea propuesta por Rodríguez Gutiérrez de Ceballos según la cual Ignacio se dejó convencer rápidamente por Mendoza (cfr. Rodríguez, 1966: 104).

30. "Cardinalis etiam de Mendoza, tunc episcopus cauriensis, postea vero Burgensis, cum Ignatium et socios ex animo diligeret, et a quodam eorum aliquid etiam auxilii in Spiritualibus Exercitationibus habere voluisset, de collegio Societatis Salmanticae instituendo agere coepit; cum autem intellexisset doctorem Michaëlem de Torres Societatem ingressum esse, atque eumdem Salmanticae mitti posse, id cardinali auditu gratissimum fuit». Chron. I, p. 210 (cfr. De León, 2019: 353-379).

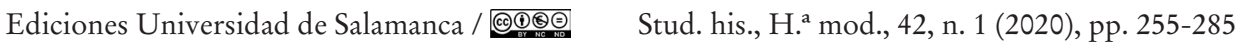


CRISTO JOSÉ DE LEÓN PERERA

RECTORES DEL COLEGIO DE LA COMPAÑÍA DE JESÚS EN SALAMANCA: APROXIMACIÓN HISTÓRICA A UN DOMICILIO UNIVERSITARIO

\section{EL PRIMER RECTOR DE SALAMANCA: MIGUEL DE TORRES}

Tras haber realizado una minuciosa presentación del proceso mediante el cual se llega a la elección del fundador del domicilio de la Compañía de Jesús en Salamanca, entendemos como oportuno presentar su figura en los contextos académico y personal.

Cuando hacemos referencia a Miguel de Torres la hacemos a una persona de gran reputación para sus coetáneos. Había sido colegial de San Idelfonso en la Universidad del cardenal Cisneros, donde recibió Grado en Artes y en Teología. Con posterioridad ostentó la Cátedra de Artes.

Como delegado de la Universidad de Alcalá partió hacia la Ciudad Eterna en busca de defenderla ante unos conflictos contra el arzobispo de Toledo, Juan de Tavera. Gracias a este viaje realizó los Ejercicios Espirituales en 1542 y posteriormente abrazó la orden, haciendo los votos en Gandía en el año 1546.

En carta de Antonio Araoz, fechada a primeros de septiembre de 1547, destina al doctor Torres camino de Italia ${ }^{31}$, encontrándose la solución a la dificultad salmantina. En el mismo septiembre de 1547 Ignacio le escribe diciendo:

[...] El cardenal don Francisco de Mendoza me pide embie algunos de los nuestros a fundar vn collegio en Salamanca, que él quiere dotar. No tengo a quien encomendar esto, sino a vuestra reverencia, y assí podrá tomar vno, o dos compañeros de los que en esse collegio de Alcalá están, y irse con ellos a Salamanca por superior ${ }^{32}$.

Ignacio de Loyola había tomado ya la decisión sobre la que se apoyará con posteridad cuando los problemas acechen a la orden en Salamanca. Nadie mejor para suplir la figura del padre Estrada que Torres. Con este jesuita, Ignacio tenía la misma estima que con el duque, siendo uno de sus principales consejeros en estas tierras hispánicas ${ }^{33}$. Quedaba señalada una de las personas más relevantes de todo el territorio peninsular para encaminarse hacia la Universidad de las dos monarquías católicas: la de la Iglesia Romana y la del Imperio español.

Francisco de Borja quedaba informado formalmente el 19 de noviembre de $1547^{34}$ y diez días más tarde, Ignacio le aportaría información más completa a Miguel de Torres sobre su destino. El 9 de febrero de 1548, acompañado del padre Pedro Sevillano (que en 1545 había sido recibido en Alcalá por el padre Francisco

31. «El doctor Torres a estado aquí, y se a ydo, para este septiembre yr a Alcalá, y de allí irse a Gandía, y leer asta que sea tiempo de pasar a Italia, y para lo de la cédula que ymbien a vuestra reverencia proveerá el duque». MHSI. Epp. Mixtae. I, p. 398.

32. MHSI. Epp. Ign. I, p. 582.

33. Sirva a modo de ejemplo la carta redactada por Ignacio el 1 de septiembre de $1547 \mathrm{y}$ destinada al padre Antonio Araoz, cfr. MHSI. Epp. Ign. I, pp. 588-590.

34. MHSI. Epp. Ign. I, pp. 635s.

Ediciones Universidad de Salamanca / 요 Stud. his., H. ${ }^{a}$ mod., 42, n. 1 (2020), pp. 255-285 
CRISTO JOSÉ DE LEÓN PERERA

RECTORES DEL COLEGIO DE LA COMPAÑÍA DE JESÚS EN SALAMANCA: APROXIMACIÓN HISTÓRICA A UN DOMICILIO UNIVERSITARIO

Villanueva), del padre Juan Bautista Sánchez y del hermano Gutiérrez ${ }^{35}$ llega a la ciudad de Salamanca el doctor Torres a fundar el domicilio de la Compañía que se convertía en uno de los más prestigiosos de todo el Orbe.

El doctor Torres, en su carta del mes de abril de 1548, solicitaba a Ignacio un aumento de los miembros de la Compañía en la ciudad ${ }^{36}$, asunto con el que Ignacio estaría conforme y, al padre Araoz, le encomendará que busque los sujetos que puedan ser útiles en este territorio ${ }^{37}$. Encomendarían al primer rector la solidificación y correcto establecimiento de la Compañía en Salamanca.

\section{SUCESORES DEL DOCTOR TORRES}

Desde el ya mencionado Miguel de Torres hasta Ignacio Osorio -padre que ostentaba el cargo de rector en el momento de la fatídica Pragmática de 1767transcurren un total de setenta y seis períodos rectorales. Debemos señalar que no estamos ante setenta y seis jesuitas diferentes, sino que en algunos casos -concretamente en diecisiete- repetían o eran llamados nuevamente. Esto se producía por diversas circunstancias; como muestra sirva la muerte de Alonso del Caño el 10 de mayo de 1643 ascendiendo al puesto de rector el padre Pedro Pimentel, hasta el momento vicerrector.

Estamos ante cincuenta y ocho miembros diferentes de la Compañía que se encontraban profundamente preparados. Sus trayectorias muestran evidentes vinculaciones con el campo de la reflexión, así como la realización anterior de diversos ministerios relacionados con el gobierno del colegio. Poseían pues, un reconocido prestigio -tanto intelectual como espiritual-dentro de su orden como en la ciudad del Tormes.

Ejemplo puede ser:

El padre doctor Pedro Sánchez, rector. Natural de San Martín, diócesis de Toledo. De treinta y ocho años, siete años y medio de Compañia. Hizo los votos luego en entrando. Es doctor en Theología por Alcalá. Antes de entrar en la Compañia era

35. Biblioteca General Histórica de la Universidad de Salamanca (USAL. BG). Ms. 1547 fol. $2 \mathrm{r}$.

36. «Es menester que aquí se haga rostro y aun algún cuerpo de gente porque, como nos ven tan pocos, no hazen caso de nosotros ny de lo que pretendemos, y andaremos siempre perdiendo crédito, et maxime no viendo edificio, ny fundamento de renta para el collegio». MHSI. Epp. Mixtae. I, p. 493.

37. Carta para el padre Araoz, fechada en Roma el 28 de abril de 1548: «[...] de Portugal dicen que embían tres a Salamanca, prometen vn otro. Vuestra reverencia verá si destos se podrá aprovechar: si no, lo mejor que se pueda, provea de otras partes a la presente necesidad, no mirando si se recibe algún daño particular, que casi no se puede escusar en los estudios». MHSI. Epp. Ign. I, pp 96s.

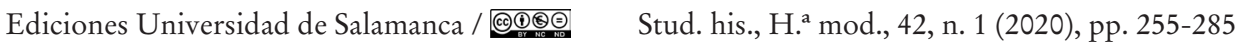


CRISTO JOSÉ DE LEÓN PERERA

RECTORES DEL COLEGIO DE LA COMPAÑÍA DE JESÚS EN SALAMANCA: APROXIMACIÓN HISTÓRICA A UN DOMICILIO UNIVERSITARIO

collegial mayor y rector de la Universidad. Leya Cáthedra de Artes y después a leydo una lectión de Theología en Valladolid y tres años de $\operatorname{Casos}^{38}$.

Se muestra una trayectoria vital considerable, de edad asentada y con reputación académica que favoreció una notable experiencia docente en varios colegios de la orden.

De igual manera, la característica movilidad de los jesuitas queda evidenciada en este puesto. No todos, ni mucho menos, fueron miembros que conocieron la orden en Salamanca. Un 24'14 \% de los rectores -que no de los períodos rectorales, por lo que en todas las cifras nos estamos refiriendo a un $76,32 \%$ - había sido admitido en este colegio; el resto posee diferentes comunidades de origen. Ser recibidos en Salamanca y llegar a rector no significaba que en ellos no se diese movilidad, todo lo contrario, se evidencian constantes traslados por toda la Provincia que nada tenían que envidiar al doctor Pedro Sánchez.

Si completamos esta cifra, a su vez, con el $53^{\prime} 45 \%$ que ostentó -antes o después del puesto de rector salmantino- el cargo de provincial se evidencia, aún más si cabe, la importancia de este domicilio con respecto del resto de la Provincia. No sólo llegarían a provincial alguno de los rectores salmantinos. La Asistencia de España también fue encabezada por los rectores del Tormes. De la treintena de jesuitas que tenían bajo su cargo a la Asistencia ente 1558 y 1767 un 13’33 \% había demostrado con anterioridad en Salamanca sus dotes en el gobierno.

A estas alturas de la lectura, la influencia de la Academia salmantina en el colegio -y viceversa- ha quedado en más de una ocasión reflejada; ésta sea tan sólo una más. Era tal el peso que conllevaba la docencia que, por norma general, mientras se encontraban en activo (tanto en las lecciones del domicilio como en las de las cátedras universitarias de Prima y Víspera de propiedad), no se encargaban del rectorado. Pero una vez que llegaba la jubilación y gozaban del merecido prestigio del cargo, se les podía encargar el oficio de rector ${ }^{39}$.

De los diecinueve jesuitas que se dedicaron a la reflexión en las cátedras de Vísperas y Prima de Teología propiedad de la orden, tan solo seis ocuparían el rectorado: Juan Barbiano Belgiojoso -único de este grupo que será rector antes que Catedrático-, Francisco Xavier, Francisco de Miranda, Fernando de Morales, Ignacio Osorio y Salvador Osorio.

Estamos haciendo referencia a tan solo un 10'34 \% del total de rectores y a un $11^{\prime} 84 \%$ de todos los períodos rectorales del domicilio. Debe contextualizarse el

38. ARSI. Provincia Castellana 13, fol. 106r.

39. En el caso de Francisco Miranda ocuparía el rectorado entre 1732 y 1734 y la jubilación no llegaría hasta 1735, cfr. Archivo Histórico de la Universidad de Salamanca (AUSA). 955, fol. 625-626.

Ediciones Universidad de Salamanca / అ@@ Stud. his., H. ${ }^{a}$ mod., 42, n. 1 (2020), pp. 255-285 
CRISTO JOSÉ DE LEÓN PERERA

RECTORES DEL COLEGIO DE LA COMPAÑÍA DE JESÚS EN SALAMANCA: APROXIMACIÓN HISTÓRICA A UN DOMICILIO UNIVERSITARIO

dato para que no lleve a equívoca interpretación. Desde la llegada del padre Torres, la orden no poseería estas cátedras, sino que habría que esperar hasta 1668 para que la reina María Ana de Austria las fundase; es decir, habían pasado ya ciento veinte años desde la llegada de la orden y tan sólo faltarían noventa y nueve para la expatriación.

Debe puntualizarse aún más. En la carta enviada para concluir el año de 1555 se le dice a Ignacio -hablando de las conclusiones y conferencias celebradas en el colegio- «[...] an venido personas principales de la Universidad, maestros, cathedráticos, collegiales de los Collegios Mayores y algunos padres dominicos; y creo van muy edificados» ${ }^{40}$.

Entre estos se encontraría probablemente a Alonso del Caño, colegial del Arzobispo de Toledo ${ }^{41}$ que logra en 1604 ocuparse del curso de Artes de la Universidad por haber quedado vacante al ser nombrado maestrescuela de la catedral de Huesca el doctor Pedro López, colegial de San Bartolomé, que hasta el momento se ocupaba de dichas lecciones ${ }^{42}$. Tras la cercanía a los jesuitas pediría su ingreso en la orden, llevándose a efecto el 31 de septiembre de $1606^{43}$, renunciando el mismo día a sus clases de $\mathrm{Artes}^{44}$. La repercusión que tenía el doctor Caño es evidente y la influencia de su renuncia en la Universidad incalculable.

Propondremos, a continuación, cuatro ejemplos - dos de ellos rectores que había ocupado alguna de las cátedras fundadas por la reina para la orden-que complementen lo presentado para Miguel de Torres y sirva como utilidad para plantear la figura prototípica del jesuita rector de Salamanca. Evidentemente no hacen referencia a la totalidad, pero sí que nos encontramos ante dos casos significativos.

\subsection{Jerónimo de Ripalda (1573; 1580-1586)}

El jesuita Jerónimo de Ripalda ${ }^{45}$ nació en Teruel $^{46}$ en 1535 . Realizó estudios universitarios en Alcalá de Henares donde conocería a la orden. En dicha Academia humanística cursó los pertinentes años de latinidad y artes.

40. Litt. Quad. III, p. 740.

41. AUSA. 2176, fol. 385-439.

42. AUSA. 974, fol. 459-470. Proceso realizado entre el 9 de abril y el 18 de junio de 1604.

43. USAl. BG. Ms. 1548, fol. 34v.

44. AUSA. 975, fol. 336-344.

45. Como es habitual para la época, en la documentación aparecen reflejados los nombres con una serie de variantes. En este caso se le denomina Jerónimo Ripalda y Jerónimo de Ripalda. Nosotros hemos optado por insertar la preposición puesto que así se refleja en los catecismos del autor conservados de la época y vinculados al colegio de Salamanca.

46. Resines Llorente aportará en su estudio sobre los catecismos de Ripalda y Astete la respuesta dada por Jerónimo al interrogatorio del padre Nadal (Litt. Quad. VI, p. 111) que

Ediciones Universidad de Salamanca / అ@@ Stud. his., H. ${ }^{a}$ mod., 42, n. 1 (2020), pp. 255-285 
CRISTO JOSÉ DE LEÓN PERERA

RECTORES DEL COLEGIO DE LA COMPAÑÍA DE JESÚS EN SALAMANCA: APROXIMACIÓN HISTÓRICA A UN DOMICILIO UNIVERSITARIO

Su padre, el médico Bernardino de Ripalda, conocía a Ignacio gracias a su estancia en Alcalá durante 1527. Este contacto le hizo poseer estima hacia el fundador de Loyola (Resines, 2001: 3364). Pero tal acontecimiento no facilitó la situación cuando, el joven Jerónimo, decidió abrazar la orden. Bernardino pidió la mediación del rector de la Universidad mediante un decreto real, quien fue convencido por Jerónimo, por lo que en 1551 entra al noviciado (Sommervogel, 1895: 1863).

Solventada esta dificultad, en 1554 se encuentra como hermano escolar formándose en Gandía. Continuaría sus estudios en Valencia y -nuevamente- en Alcalá. En estos periplos profundizaría en Artes (obteniendo la maestría) y Teología.

Enseñó Casos de Conciencia en los domicilios de Valladolid (1562 y 1566) y Ávila (1564). En el año 1568 se encontraba nuevamente en Valladolid desempeñando el cargo de procurador, título que ejerció en el mismo año para la Provincia de Castilla en el transcurso de la i Congregación de procuradores de Roma.

En 1570 comenzó su mandato de rector de la Casa Profesa de Valladolid (hasta 1572). En el año 1573 ocupó el mismo cargo en el colegio de Salamanca. En 1577 fue rector de Burgos y, en el período que transcurre entre 1580-1586, aparece nuevamente como rector de Salamanca ${ }^{47}$. Finalmente lo encontramos en Villagarcía (a donde fue trasladado en junio de 1585), ostentando el cargo de rector, después de ser absuelto por la Inquisición en Valladolid tras haber estado preso dos años.

Ejerció, también, los ministerios de confesor y de maestro de novicios (Resines, 1987: 206). Debido al ejercicio apostólico del sacramento de la penitencia destacaría en su estancia salmantina entre el gremio universitario. En el libro teresiano conocido como Fundaciones ${ }^{48}$, en su prólogo, nos dice:

[2] Abora, estando en Salamanca, año de mil y quinientos y setenta y tres, que son once años después, confesándome con un padre rector de la Compañia, llamado el maestro Ripalda, habiendo visto este libro de la primera fundación, le pareció sería servicio de nuestro Señor que escriviese de otros siete monesterios que después acá, por la bondad de nuestro Señor, se han fundado, junto con el principio de los monesterios de los padres descalzos de esta primera orden, y ansi me lo ha mandado.

Pero esta no será la única aportación realizada por el padre Ripalda en el ámbito de la piedad. Aunque no lo desarrollaremos en este momento, debemos indicar que,

se conserva custodiada en la Universidad Pontificia de Comillas: «Nací en Teruel, pero me he criado en Castilla, en Escalona» (Resines, 1987: 203).

47. Resines Llorente (2001: 3365) no señala la primera estancia en Salamanca.

48. A pesar de que la Santa Castellana no puso título alguno a este libro se le conocer por dicho nombre. Nosotros utilizaremos la edición de Obras Completas. Edición manual. Transcipción, introducciones y notas de los padres Efrén de la Madre de Dios O.C.D y Otger Steggink O. CARM. Biblioteca de Autores Cristianos: Madrid, 1962.

Ediciones Universidad de Salamanca / 요 Stud. his., H. ${ }^{a}$ mod., 42, n. 1 (2020), pp. 255-285 
desde los inicios del colegio de Salamanca se realizaba -al igual que en la mayoría de los domicilios de la orden- la enseñanza de la Doctrina para niños todas las doménicas, para las cuales utilizarían el famoso Catecismo de Ripalda-segundo Catecismo de Astete (cfr. Resines, 1996: 89-138)-, siendo su primer ejemplar conservado de 1591 (Hernández, 1984: 360-362).

Hay que decir finalmente que, murió en Toledo (el 21 de abril de 1618) donde se encontraba desde 1594, después de una prolongada vejez y de una larga trayectoria vital en la que dejó puestas las bases para ser considerado uno de los teólogos y catequistas más importantes, no sólo de la Provincia de Castilla, sino de todo el siglo $\mathrm{xvI}^{49}$. Su nombre quedaba vinculado de forma explícita a la Doctrina Cristiana y a la indudable calidad de la labor catequética, siguiendo el pensamiento de Astete, en la ciudad y gremio de Salamanca gracias a su modelo kerygmático unificado en todo el territorio de la Corona Hispana.

\subsection{Juan Barbiano Belgiojoso (1664-1666)}

El padre Barbiano es, él en todo su conjunto, una sucesión de complejidades relacionadas con diversas dificultades; esto se debe en gran parte a su trayectoria salmantina. Se trata, por tanto, de una personalidad que, cuanto menos, es atrayente en toda su figura.

Lo primero que debe ser indicado es el análisis realizado por Apolinar de Morán (1950: 85-142; cfr. Martínez, 2001: 343-344) relacionado con este jesuita. Nosotros matizaremos la información, aportando referencias correspondientes a diversos archivos que no fueron utilizados al realizarla.

A su vez, es necesario indicar que la trayectoria de Barbiano quedó marcada por una serie de acontecimientos convulsos. Durante su vida se observa una verdadera transformación, no sólo intelectual o personal, sino también en sus relaciones dentro de la propia institución a la cual pertenecía: la Compañía de Jesús. Diversos son los motivos, entre ellos señalar que pudo ver cómo la orden le dio la espalda en un primer momento -respaldando a Pedro Abarca- para, con posterioridad, denominarle como uno de los sujetos de la orden con mayor virtud de toda la Provincia de Castilla ${ }^{50}$.

$\mathrm{Al}$ señalar su nacimiento remarcamos también la internacionalidad de esta figura: una de tantas proyecciones del colegio salmantino y de su figura rectoral. Nació en

49. A pesar de esto no debe olvidarse que, siendo rector de Villagarcía de Campos fue apresado por el Tribunal de la Inquisición de Valladolid entre 1586 y 1588 (Burrieza, 2013:515).

50. «Fue el padre Barbiano uno de los mayores sujetos que ha tenido esta Provincia en virtud insigne y todo género de letras, adorado de la Corte de esta Universidad como un oráculo de santidad y de sabiduría». USAL. BG. Ms. 1575, fol. 128r.

Ediciones Universidad de Salamanca / అ@@ Stud. his., H. ${ }^{a}$ mod., 42, n. 1 (2020), pp. 255-285 
CRISTO JOSÉ DE LEÓN PERERA

RECTORES DEL COLEGIO DE LA COMPAÑÍA DE JESÚS EN SALAMANCA: APROXIMACIÓN HISTÓRICA A UN DOMICILIO UNIVERSITARIO

Milán el 20 de abril de $1614^{51}$ y sus progenitores fueron el conde Alberico Barbiano Belgiojoso y la condesa Julia Asaybata.

De esto poseemos constancia gracias a un manuscrito conservado en la Biblioteca General histórica de la Universidad de Salamanca que corresponde al Segundo libro de los recibos de la Compañia de Jesús en dicho territorio. El juramento de Barbiano corresponde a uno de los que más información aportan de todos los conservados y señala lo siguiente:

Digo yo, don Juan Barbiano Belgiojoso, natural de la ciudad de Milán. Hijo del conde Alberico Barbiano Belgiojoso y de la Condesa Julia Asaybata. De edad de veintiun años. Que me mostraron el libro de el examen y sumario y bulas que tratan del instituto de la Compañia y me declararon las cosas que en su instituto pueden tener dificultad y soy contento de vivir en la Compañía, observando todo lo que se me ha propuesto de su instituto y habiéndome leydo y propuesto la regla de la corrección fraterna que se usa en la Compañia, dije la tenía por buena y renunciaba qualquier desecho que pudiere para avisar mis faltas antes, y se dé noticia a los superiores de la Compañia. Y si en algún tiempo se ofreciere alguna dificultad o duda acerca de los votos o instituto de la Compañia o en socorrer a mis parientes o hermanos estoy resuelto a sujetar mi parecer a los superiores de la Compañía y determinación. Fui examinado y preguntado en los impedimentos essenciales, si ay para entrar en la Compañia, y digo que no tengo ninguno dellos y por ser verdad, lo firmé de mi nombre en Salamanca a 4 de abril de 1635.

\section{Diego Bonifaz [rúbricca]. Don Juan Barbiano Belgiojoso [rúbricca $]^{52}$.}

Seguidamente, se indica que «[...] llevóle al noviciado el padre Antonio Pérez», célebre teólogo que fue profesor tanto en Salamanca como en el Colegio Romano. Lo cual muestra la importancia que poseían las lecciones del domicilio salmantino más allá del ámbito meramente cultural.

Tras su estancia en el noviciado, en el curso 1639-1640 volvió a tierras charras para dar comienzo a sus estudios de Teología en la Universidad de la Corona ${ }^{53}$. Gracias a la matrícula del curso siguiente podemos saber que antes de San Lucas de

51. Esta fecha la hemos obtenido del libro de recibos cuya referencia trataremos a continuación. Martínez (2001: 343) señala como posibilidad que sea también 1615. Morán (1950: 93) a pesar de realizar una biografía de este jesuita no propone fecha alguna.

52. USAL. BG. Ms. 1548, fol. 90v. Según Morán (1950: 93) el apellido de su madre posee la variante Afaybata.

53. AUSA. 347 fol. 9v. Podemos indicar que ha comenzado sus estudios de Teología en Salamanca gracias a la matrícula del curso de 1641-1642 (AUSA. 349 fol. 8r) en la que se señala «padre Juan Barbiano, teólogo $3^{\circ}$ ».

Ediciones Universidad de Salamanca / అ@@ Stud. his., H. ${ }^{a}$ mod., 42, n. 1 (2020), pp. 255-285 
CRISTO JOSÉ DE LEÓN PERERA

RECTORES DEL COLEGIO DE LA COMPAÑÍA DE JESÚS EN SALAMANCA: APROXIMACIÓN HISTÓRICA A UN DOMICILIO UNIVERSITARIO

1640 poseía el ministerio presbiteral ${ }^{54}$. Continúa su trayectoria académica llegando en cuarto curso a celebrar su primer Acto Menor en la Universidad, concretamente el 28 de enero de $1643^{55}$; aunque éste no será el único que protagonizará.

Llegados a este punto, había terminado ya sus estudios y sería trasladado al colegio de San Ambrosio de Valladolid. Durante cuatro años (1640-1644) explicó la Filosofía de Aristóteles -temática por la que solían comenzar todos los maestros de Teología- con la salvedad de que nuestro jesuita aún no lo es. Seguidamente, de 1648 a 1651 expondrá -también en las clases de San Ambrosio- las diversas materias de la Teología $a^{56}$.

Aunque durante todo este tiempo no perdería su vinculación con Salamanca (puesto que realizó alguna visita ${ }^{57}$ ) debemos esperar al curso de 1651-1652 para que vuelva a las tierras del Tormes de forma definitiva, continuando con su vida académica tras matricularse en la Universidad ${ }^{58}$. Lo cierto es que hasta ahora nada sorprendente más allá de su inteligencia y amplio conocimiento demostrado en sus lecciones.

Junto con las ánimas de 1652 se avecinó una etapa imprescindible, no sólo para su figura, sino para todo el colegio de la Compañía de Jesús en Salamanca -el ya Colegio Real-. El 22 de noviembre se licenció ${ }^{59}$ en Teología y, seis días más tarde, recibió la maestría ${ }^{60}$. Estos acontecimientos serán descritos minuciosamente en el Diario interno del colegio, pues reconocían la importancia del acto que estaba aconteciendo ${ }^{61}$. Puesto que la referencia no se encuentra exclusivamente en los procesos de obtención de tales títulos, no logramos saber de dónde proceden las fechas que Benigno Hernández señala puesto que tampoco indicará su fuente ${ }^{62}$.

A partir de este momento se dedicó casi en exclusividad a la enseñanza. En el curso de 1652-1653 $3^{63}$ fue maestro de estudiantes y en adelante, hasta el curso de 1663-1664 fue el maestro de Teología del domicilio de la Compañía de Jesús en

54. AUSA. 348, fol. 9v.

55. USAL. BG. Ms. 576, fol. 232v.

56. Morán (1950: 94) difiere en las fechas propuestas.

57. USAL. BG. Ms. 577, fol. 19r.

58. AUSA. 359 , fol. 10 r.

59. AUSA. 785 fol. $151 \mathrm{r}$.

60. AUSA. 786, fol. 155r.

61. USAL. BG. Ms. 577 fol. 156r.

62. «Fue el 11-XI-1652 cuando por primera vez los jesuitas se graduaron de maestros en la Universidad salmantina: los tres primeros graduados fueron los padres del colegio Bernardo de Alderete, Ricardo Lince (o Lynch, irlandés) y Juan Barbiano (milanés)» (Hernández, 1989: 402).

63. AUSA. 360 , fol. $8 \mathrm{v}$. 
CRISTO JOSÉ DE LEÓN PERERA

RECTORES DEL COLEGIO DE LA COMPAÑÍA DE JESÚS EN SALAMANCA: APROXIMACIÓN HISTÓRICA A UN DOMICILIO UNIVERSITARIO

Salamanca ${ }^{64}$. En este período, concretamente en mayo de 1653, realizó sus cuatro $\operatorname{votos}^{65}$.

Teniendo ya cierto reconocimiento, a la muerte del padre Francisco de Vergara, rector, el padre provincial -el 6 de febrero de $1664-$ le nombró vicerrector ${ }^{66}$. Posteriormente, el 28 de diciembre del mismo año, ascendió al gobierno rectoral del domicilio.

Se coronaría solicitando a la Reina Gobernadora la gracia de erección de dos cátedras de propiedad de la orden -Prima y Vísperas de Teología- que gozasen de los mismos privilegios que las existentes para el resto de las órdenes religiosas ${ }^{67}$. El lunes 30 de abril de 1668 se inaugurarían las lecciones, ocupando el padre Barbiano la de Prima ${ }^{68}$. A partir de este momento, dejó el puesto de rector para poder ocuparse en plenitud a la erudición teológica.

Hasta ahora se observa una trayectoria modélica, pero las suertes no tardarían en tornar. Esta reflexión, sobre todo en las materias relacionadas con la humanidad de Cristo y la visión intuitiva de María en su vida mortal, le terminaron rodeando de la duda heterodoxa e inevitablemente envolviéndole en la controversia.

Lo curioso de todo es que Barbiano fue refutado por la propia orden, concretamente el encargado para este menester fue su sucesor en la cátedra, Pedro Abarca. El padre general se posicionaba al lado de Abarca, al igual que el asistente, impidiéndose de esta manera su promoción al cardenalato. Los maestros y los estudiantes del colegio jesuítico se encontraban divididos a causa de este asunto ${ }^{69}$. No estamos haciendo mención de un asunto baladí, sino que se trata de una controversia que salió más allá de los muros del recinto colegial ${ }^{70}$.

El prestigio que había adquirido el acusado contribuyó notablemente a la resonancia de las disputas. Era tal el disturbio y las versiones enfrentadas sobre el

64. AUSA. 361, fol.7r; AUSA. 371, fol. 8v.

65. USAL. BG. Ms. 357 fol. 286r.

66. Morán (1950: 96) señala que esto se produce en 1644, lo cual, entendemos que se debe a un error de redacción.

67. Creemos que USAL. BG. Ms. 378, fol. 30-34, corresponde con el borrador. En los folios 27-29 de dicho manuscrito encontramos otro informe, dirigido al presidente del Consejo de Castilla, sobre el mismo asunto (cfr. Burrieza, 2002: 149-186).

68. «30. Lunes. Se comienzan a leer nuestras cátedras a la misma hora que las demás de la Universidad y en el general señalado por la Universidad y confirmado por el Consejo». USAL. BG. Ms. 578 fol. 47v.

69. USAL. BG. Ms. 161 fol. 115r-116r.

70. «Hasta en las 'gacetas' de Holanda se corrió que el maestro jesuita de Prima de la Universidad de Salamanca había sido arrojado de la cátedra por hereje» (Morán, 1950: 122).

Ediciones Universidad de Salamanca / @®@@ Stud. his., H. ${ }^{a}$ mod., 42, n. 1 (2020), pp. 255-285 
veredicto que decidieron hacerlo llegar al Santo Oficio, quien las señaló al margen de sospecha ${ }^{71}$.

Los superiores de la orden deciden hacer caso omiso a las advertencias. La forma que vieron oportuna para que no se repitiese tal conflicto, comprometiendo nuevamente a la orden, sería apartar al padre Barbiano de la enseñanza. Como es evidente, éste se resistió en sus inicios, pero su espíritu de obediencia -enseñado a ejercitar desde el noviciado- le llevó a aceptar esta decisión.

Para un religioso destinado a la erudición y la enseñanza, la Cátedra de Prima de Salamanca equivaldría a la silla de la Sede Primada; en ella se manifestaba el culmen de su carrera. Un sueño logrado, palpado y arrebatado que, como consuelo para su tedio, se le recompensaría -postmortem - con el vítor de la fachada del Colegio Real, único recuerdo de sus momentos de esplendor que conservaría hasta su muerte el 5 de septiembre de 1676 .

Terminaremos la figura de Juan Barbiano tal y como la empezamos, recordando que se trata de un conjunto de complejidades. Uno de los sujetos más relevantes de su tiempo, capaz de hacer, con su erudición, llevar el nombre del colegio de Salamanca fuera de las fronteras de la Provincia.

\subsection{Gregorio Sarmiento (1683-1685; 1692-1694)}

En un primer lugar el padre Gregorio Sarmiento brillaba por la carencia de información que poseíamos sobre su persona. Somos conscientes de que los datos que vamos a señalar a continuación deben ser ampliados, pero se trata de lo que nos han aportado las fuentes consultadas.

Nació en 1640 y fue recibido con dieciocho años en la Compañía ${ }^{72}$. La primera referencia que tenemos relacionada con el Colegio Real -del aún entonces hermanose debe al libro de matrícula universitaria correspondiente al curso $1663-1664^{73}$. El hermano Sarmiento llegó al domicilio salmantino para cursar Teología tras haber, posiblemente, acabado sus estudios de Gramática, probablemente en Villagarcía de

71. Aunque no poseemos el original de la sentencia, hemos localizado: «Copia authentica deste auto asi lo provieron y mandaron y señalaron sus excelencias señores don Francisco de Lara, lizenciado don Martín Castellón, lizenciado don Antonio Caballero, lizenciado don Fernando de Villegas, lizenciado don Antonio de Aiala Verganza, doctor don Manuel González Téllez, Lizenciado don Diego de [non legitur] secretario del Consejo. Concuerda con su original». Real Academia de la Historia (RAH). Ms. 9-3617/4.

72. ARSI. Provincia Castellana 18.I, fol. 6r-8r.

73. AUSA. 371, fol. 9r. 
CRISTO JOSÉ DE LEÓN PERERA

RECTORES DEL COLEGIO DE LA COMPAÑÍA DE JESÚS EN SALAMANCA: APROXIMACIÓN HISTÓRICA A UN DOMICILIO UNIVERSITARIO

Campos. Continúa reflejado en la matrícula universitaria de los cursos 1664-1665 $1665-1666^{75}, 1666-1667^{76}$.

En el transcurso de 1667 debió recibir el ministerio sacerdotal puesto que, en el curso 1667-1668 aparece matriculado -el «30 de dezembre 1667»-como padre Gregorio Sarmiento ${ }^{77}$. Lamentablemente no podemos afinar con mayor precisión en el momento que recibió de manos del obispo de Salamanca las órdenes mayores. En el transcurso del curso $1668-1669^{78}$ continuó en el gremio universitario del Tormes.

Le perdemos la pista hasta el curso $1673-1674^{79}$ que mantuvo su formación en la Academia salmantina, al igual que en los sucesivos cursos de $1674-1675^{80}, 1675-$ $1676^{81}$. Antes de volver a ser trasladado al concluir el curso académico de 1676, el 2 de febrero de 1675, junto con los padres Francisco Xavier y Diego Valledor, realizaría su profesión de cuatro votos en el Colegio Real ${ }^{82}$.

No podemos indicar con certeza cuándo retornará al Colegio del Espíritu Santo. En el año $1681^{83}$ se encuentra en Salamanca, pero no está matriculado en la Universidad. Intuimos que se encontraba realizando las lecciones propias de la orden en el recinto colegial.

Posiblemente debido a su nombramiento como rector del colegio vuelve a realizar presencia en el gremio universitario matriculándose en los cursos 1683-1684 ${ }^{84}$, 1684-1685 ${ }^{85}, 1685-1686^{86}$. La cabeza de la Compañía en la ciudad universitaria no podía quedar desvinculada de su Academia, aunque, según la información que poseemos, no logró graduarse en Teología ${ }^{87}$.

Tras su primer rectorado vuelve a ser trasladado de Salamanca. En 1689 ocupó el cargo de provincial por lo que continuaría manteniendo ciertas visitas a Salamanca, al menos para revisar que todo se encontraba en correcto funcionamiento y asistirles espiritualmente; estancias que eran aprovechadas para realizar los votos delante del

74. AUSA. 372, fol. 14r.

75. AUSA. 373 , fol. $14 \mathrm{v}$.

76. AUSA. 374, fol. $18 \mathrm{v}$.

77. AUSA. 375, fol. 13 r.

78. AUSA 376, fol. 16v.

79. AUSA. 381 , fol. $11 \mathrm{v}$.

80. AUSA. 382 , fol. $7 \mathrm{v}$.

81. AUSA. 383, fol. $13 \mathrm{v}$.

82. USAL. BG. Ms. 357 fol. 292v.

83. ARSI. Provincia Castellana 19, fol. 205r.

84. AUSA. 391, fol. 9r.

85. AUSA. 392, fol. 13v.

86. AURA. 393 , fol. 12 r.

87. ARSI. Provincia Castellana 19, fol. 205r. Catálogo Trienal de 1681 en el cual otros padres, compañeros en la matrícula universitaria en los años señalados anteriormente, si aparecen reflejados con dicho grado.

Ediciones Universidad de Salamanca / @@ Stud. his., H. ${ }^{a}$ mod., 42, n. 1 (2020), pp. 255-285 
provincial, como es el caso del hermano Francisco Zelayarán, que realizaría sus votos simples delante del padre Sarmiento ${ }^{88}$.

En 1692 volvió a Salamanca para ocupar el puesto de rector hasta 1694. Nuevamente, igual que en el período anterior, estará presente en las matrículas de los cursos universitarios de $1692-1693^{89}, 1693-1694^{90}$ y $1694-1695^{91}$.

A pesar de no ostentar las lecciones de una de las cátedras de propiedad de la orden en las Escuelas Mayores observamos una verdadera vinculación del rector del colegio de la Compañía con el ambiente intelectual representado por el gremio de la Universidad.

En el año 1696 lo encontramos ejerciendo el puesto de asistente de España, por lo que su valía queda evidenciada con esta guinda en su trayectoria. Un hombre que no se dedicó especialmente a la reflexión intelectual, pero que poseía indudables dotes para la acción gubernamental. Falleció el 29 de octubre de 1707 en el colegio de San Ambrosio de Valladolid"2.

\subsection{Francisco Xavier (1695-1696; 1701-1703)}

Francisco Xavier representa el prototipo de vida dedicada a la formación y al estudio del colegio de Salamanca, pero vayamos por partes. Nace -aproximadamente- en 1640; sus padres son don Bernardo de Garro y Xavier, conde de Javier, y doña Ana María de Arizcun y Beaumont ${ }^{93}$.

La primera noticia de su presencia en Salamanca la tenemos en la antevíspera de $1663^{94}$, en matrícula universitaria. Un Francisco Xavier que, de momento, deja duda si posee órdenes mayores o no. El día de la Purificación de nuestra señora de 1663, en la sacristía del colegio, realiza los tres votos ${ }^{95}$. En el curso $1663-1664^{96}$ salimos ya de dudas, Francisco es hermano estudiante. Durante los cursos académicos de $1664-1665^{97}$ y $1665-1666^{98}$ continúa su formación sin mayor novedad.

88. USAL. BG. Ms. 357, fol. 36v. Votos realizados el 3 de abril de 1689.

89. AUSA. 391, fol. 9r

90. AUSA. 392, fol. 13v.

91. AUSA. 393, fol. 12r.

92. USAL. BG. Ms. 1575, fol. 56r.

93. AUSA. 788, fol. 125v.

94. AUSA. 370, fol. 13v.

95. USAL. BG. Ms. 357, fol. 99v.

96. AUSA. 371, fol. 8v.

97. AUSA. 372, fol. 13r.

98. AUSA. 373 , fol. $14 \mathrm{v}$.

Ediciones Universidad de Salamanca / @@ Stud. his., H. ${ }^{a}$ mod., 42, n. 1 (2020), pp. 255-285 


\section{CRISTO JOSÉ DE LEÓN PERERA \\ RECTORES DEL COLEGIO DE LA COMPAÑÍA DE JESÚS EN SALAMANCA: APROXIMACIÓN HISTÓRICA A UN DOMICILIO UNIVERSITARIO}

Antes del 14 de enero de 1667 recibiría el ministerio sacerdotal, lo cual no impide que continúe sus estudios en los cursos $1666-1667^{99}$ y $1667-1668^{100}$. En este momento es trasladado pues, en 1669 deja de ser reflejado -momentáneamenteentre los habitantes del Colegio Real ${ }^{101}$.

Nuevamente en el curso de 1671-1672 ${ }^{102}$ se encuentra en Salamanca. El 9 de noviembre de 1672 recibirá la licenciatura en Teología ${ }^{103}$ y trece días después la maestría en la Universidad de Santo Tomás de Ávila, incorporando dicho título en Salamanca tras la vuelta a su colegio ${ }^{104}$. A partir de este momento continuará vinculado a la Universidad sin novedad alguna hasta que, en septiembre de 1686, concretamente el día 11, el padre maestro Francisco Maldonado ascendía a la Cátedra de Prima de propiedad, quedando vacante la de Vísperas de la misma naturaleza. El 19 de octubre de 1686 el monarca proveía la Cátedra de Vísperas, que acabamos de mencionar, en el padre maestro Francisco Xavier ${ }^{105}$.

Ostentó la Cátedra de Vísperas hasta que -casi tres años exactos más tardequedase Prima vacante por fallecimiento de su tutelar y Carlos II nombrase como catedrático de Prima a Xavier ${ }^{106}$. En 1695, estando todavía en activo en la Universidad, sería nombrado rector del Colegio Real hasta que en abril de 1696 solicite la jubilación ${ }^{107}$; seguidamente, en 1697 , sería trasladado para ocupar el cargo de provincial.

Volverá a Salamanca con el cambio de centuria. En el curso 1701-1702 ${ }^{108}$ aparece nuevamente matriculado en el gremio universitario como «[...] cathedrático de Prima jubilado, rector». El puesto rectoral lo ostentó en este segundo período hasta $1703^{109} \mathrm{y}$, en Salamanca, permanecerá hasta el curso 1706-1707110.

De suma importancia es remarcar que realizó toda su carrera académica en la Universidad de Salamanca. Pasa de ser hermano estudiante a licenciado, seguidamente maestro - por reconocimiento del título- y, finalmente, a ostentar las dos cátedras de la orden. Su reflexión sería utilizada para el gobierno en sus dos etapas

\footnotetext{
99. AUSA. 374 , fol. $18 \mathrm{r}$

100. AUSA. 375 , fol. 13 r.

101. ARSI. Provincia Castellana 18.I, fol. 101r-103r.

102. AUSA 379, fol. $7 \mathrm{v}$.

103. AUSA. 788, fol. 125 r.

104. AUSA. 788, fol. 129r.

105. AUSA. 995, fol. 596r-597v.

106. AUSA. 995, fol. 598r-599r.

107. AUSA. 995, fol. 602r-603r.

108. AUSA. 409, fol. 17r.

109. AUSA. 411, fol. 19v.

110. AUSA. 414 , fol. $13 \mathrm{v}$.
}

Ediciones Universidad de Salamanca / @@ Stud. his., H. ${ }^{a}$ mod., 42, n. 1 (2020), pp. 255-285 
CRISTO JOSÉ DE LEÓN PERERA

RECTORES DEL COLEGIO DE LA COMPAÑÍA DE JESÚS EN SALAMANCA:

APROXIMACIÓN HISTÓRICA A UN DOMICILIO UNIVERSITARIO

rectorales salmantinas y en el ejercicio del cargo de provincial de Castilla. Murió el 10 de septiembre de 1718 en Pamplona ${ }^{111}$.

\section{A MODO DE CONCLUSIONES}

Ignacio de Loyola, evocando seguramente la primera epístola paulina a los Corintios ${ }^{112}$, en una carta enviada al hermano Juan Bautista, dirá que «[...] en el cuerpo no todos son ojos, orejas, manos o pies; y como cada miembro tiene su oficio y queda contento de ello, así también en el cuerpo de la compañía no todos pueden ser letrados ni sacerdotes, sino que cada uno ha de estar contento con el oficio que le toque según la voluntad y juicio del superior, el cual ha de rendir cuentas a Dios nuestro Señor de todos los suyos» ${ }^{113}$. Expone una diferenciación por grados dentro de los miembros del instituto fundamentándola en una verdadera sucesión de obediencias; sobre todo tras quedar evidenciada su necesidad tras los primeros recorridos de la orden.

Cierto es que, en la bula fundacional, no era posible aceptar en la Compañía personas que no poseyesen una calidad intachable. Tras las experiencias ignacianas de Alcalá y Salamanca, se observó que la formación intelectual era necesaria para poder ejercitar la labor apostólica, jugando en este punto los colegios un papel fundamental.

En junio de 1546, con el breve Exponi nobis se permitió la admisión de coadjutores o miembros asociados, amén de los padres profesos pensados en sus inicios. Quedaba, pues, representada una verdadera pirámide, en cuya cúspide hallamos los profesos. Una verdadera representación social que posee sus propias referencias con respecto a las normas aceptadas, favoreciéndose una identidad cultural característica de estos domicilios de la orden ${ }^{114}$.

El colegio -y sus habitantes- representaban una forma particular del todo, una parte regional de una orden internacional. Por esta razón, inevitablemente poseía una élite (los profesos) de gobierno que solía estar caracterizada por su profunda intelectualidad, imitando los modelos propuestos por el robustecimiento de poder

111. USAL. BG. Ms. 1575, fol. 61r.

112. «Pues del mismo modo que el cuerpo es uno, aunque tiene muchos miembros, y todos los miembros del cuerpo, no obstante, su pluralidad, no forman más que un solo cuerpo, así también Cristo». 1 Corintios 12, 12.

113. MHSI. Epp. Ign. XI, pp. 437. Con fecha de Roma a 23 de mayo de 1556.

114. «Tanto 'civilización' como 'cultura' hace referencia a la forma global de vida de un pueblo [o de un grupo de individuos]. [... valores, normas, instituciones y formas de pensamiento a las que sucesivas generaciones dentro de una sociedad dada han contribuido una importancia fundamental. Para Braudel, una civilización es un espacio, un ámbito cultural, un conjunto de características y fenómenos culturales» (Huntington, 2005: 49).

Ediciones Universidad de Salamanca / అ@@ Stud. his., H. ${ }^{a}$ mod., 42, n. 1 (2020), pp. 255-285 
propio de las monarquías autoritarias que pretendían evitar inseguridades ante posibles acusaciones.

Estos profesos ostentarán todos los períodos rectorales existentes en el colegio de Salamanca. De esta manera se mantuvo la visión inicial del instituto y lo expuesto en su bula confirmatoria. Un domicilio destinado a la formación intelectual de toda la Provincia y que en su cabeza se situaba aquel que cumpliese una serie de habilidades más sobresalientes que las indispensables.

Aunque en un primer momento pueda parecerlo, no hemos pretendido caer en el error de hacer una historia de las élites, sino que inevitablemente (respetando el pensamiento reflejado en la iv parte de las Constituciones) la orden encomendó el gobierno de su átomo local, el colegio, a una minoría preparada e idónea ${ }^{115}$ : el padre rector. Una de tantas representaciones de la «nobleza local» que poseyó Salamanca.

En Salamanca se observa cómo, aunque siempre los rectores del domicilio charro habían logrado fama gracias a las lecciones impartidas con anterioridad en el cargo, se va optando a la elección de los jesuitas que han gozado de una de las cátedras de propiedad de la orden. Nos debemos situar en el período de los primeros Borbones cuando, en el contexto de la Academia universitaria, los poderes tienden a desequilibrarse en beneficio de los catedráticos frente a las figuras gremiales de rector y consiliario.

La evolución de la institución jesuítica se encuentra plenamente relacionada con la universitaria. Como consecuencia de las crisis académicas, los responsables de la Compañía buscaron adelantarse a tal situación en su propia organización mediante el refuerzo de su máximo representante en Salamanca -el rector-, recayendo dicha dignidad en un catedrático.

\section{LOS RECTORES DEL COLEGIO DE SALAMANCA}

A modo de apéndice, a continuación, se presenta una relación de los diversos períodos rectorales (y sus principales características) por los que atravesó la Compañía de Jesús en Salamanca según la información obtenida de la documentación manuscrita interna del antiguo colegio.

115. «E. Idóneos entiendo teniendo respecto a la suficiencia de las personas y a las ocupaciones; porque los officios que traen consigo mucha ocupación, no convendrían a los muy ocupados en otras cosas; y porque algunos piden experiencia para hacerse bien, no debrían fácilmente mudarse». Constituciones, 429.

Ediciones Universidad de Salamanca / అ@@ Stud. his., H. ${ }^{a}$ mod., 42, n. 1 (2020), pp. 255-285 
CRISTO JOSÉ DE LEÓN PERERA

RECTORES DEL COLEGIO DE LA COMPAÑÍA DE JESÚS EN SALAMANCA: APROXIMACIÓN HISTÓRICA A UN DOMICILIO UNIVERSITARIO

\begin{tabular}{|c|c|c|c|c|c|c|c|c|}
\hline \multicolumn{2}{|c|}{ Períodos rectorales: setenta y seis } & \multicolumn{7}{|c|}{$\begin{array}{l}\text { Número de jesuitas: } \\
\text { cincuenta y ocho }\end{array}$} \\
\hline Período de rectorado & Padre rector & A & $\mathrm{C}$ & $\mathrm{P}$ & $\mathrm{R}$ & V & VP & $\mathrm{H}$ \\
\hline $1548-1554$ & Miguel de Torres & & & & & & & \\
\hline $1555-1558$ & Bartolomé Hernández & & & & $\mathrm{X}$ & & & \\
\hline 1559 & García de Zamora & $X$ & & & & & & \\
\hline $1560-1564$ & Bartolomé Hernández & & & & $\mathrm{X}$ & & & \\
\hline 1565 & Juan Ramírez & & & & & $\mathrm{X}$ & & \\
\hline $1566-1567$ & Pedro Sánchez o Sanz & & & & $\mathrm{X}$ & & & \\
\hline 1568 & Martín Gutiérrez & & & & $\mathrm{X}$ & & & \\
\hline 1569 & Pedro Sánchez o Sanz & & & & $\mathrm{X}$ & & & \\
\hline $1570-1572$ & Martín Gutiérrez & & & & $\mathrm{X}$ & & & \\
\hline 1573 & Jerónimo de Ripalda & & & & $\mathrm{X}$ & & & \\
\hline $1574-1575$ & Baltasar Álvarez & & & & & & & \\
\hline $1576-1579$ & Antonio Marcen & & & $X$ & & & & \\
\hline $1580-1586$ & Jerónimo de Ripalda & & & & $\mathrm{X}$ & & & \\
\hline $1587-1588$ & Alonso Ferrer & $\mathrm{X}$ & & $\mathrm{X}$ & $\mathrm{X}$ & $\mathrm{X}$ & & \\
\hline $1589-1592$ & Juan Francisco Labata & $\mathrm{X}$ & & & & $\mathrm{X}$ & $\mathrm{X}$ & \\
\hline 1593 & Cristóbal de los Cobos & & & $\mathrm{X}$ & $\mathrm{X}$ & & & \\
\hline $1594-1596$ & Basilio Vique & & & & & & & \\
\hline $1597-1600$ & José de Acosta & & & & & & & \\
\hline $1601-1602$ & Alonso Ferrer & $\mathrm{X}$ & & $\mathrm{X}$ & $\mathrm{X}$ & $\mathrm{X}$ & & \\
\hline $1603-1605$ & Cristóbal de los Cobos & & & $\mathrm{X}$ & $\mathrm{X}$ & & & \\
\hline $1606-1609$ & Francisco Girón & $\mathrm{X}$ & & & $\mathrm{X}$ & & & \\
\hline $1610-1611$ & Antonio Padilla & & & & & & & \\
\hline $1612-1618$ & Francisco Girón & $\mathrm{X}$ & & & $\mathrm{X}$ & & & \\
\hline $1619-1621$ & Juan de Montemayor & & & $\mathrm{X}$ & & $\mathrm{X}$ & & \\
\hline 1622 & Miguel de San Román & & & & & & & \\
\hline $1623-1625$ & Francisco de Prado & $\mathrm{X}$ & & $\mathrm{X}$ & & & & \\
\hline $1626-1628$ & Alonso del Caño & $\mathrm{X}$ & & $\mathrm{X}$ & $\mathrm{X}$ & & & \\
\hline $1629-1631$ & Juan de Montemayor & & & $\mathrm{X}$ & & $\mathrm{X}$ & & \\
\hline 1632 & Tomás Ruiz Villalva & $\mathrm{X}$ & & & & & & \\
\hline $1633-1634$ & Gaspar de Figuera & & & & & & & \\
\hline
\end{tabular}


CRISTO JOSÉ DE LEÓN PERERA

RECTORES DEL COLEGIO DE LA COMPAÑÍA DE JESÚS EN SALAMANCA: APROXIMACIÓN HISTÓRICA A UN DOMICILIO UNIVERSITARIO

\begin{tabular}{|c|c|c|c|c|c|c|c|c|}
\hline Período de rectorado & Padre rector & A & $\mathrm{C}$ & $\mathrm{P}$ & $\mathrm{R}$ & $\mathrm{V}$ & VP & $\mathrm{H}$ \\
\hline $1635-1640$ & Gabriel de Puebla & $\mathrm{X}$ & & & & & & \\
\hline $1641-1643$ & Alonso del Caño & $\mathrm{X}$ & & $\mathrm{X}$ & $\mathrm{X}$ & & & \\
\hline $1644-1645$ & Pedro Pimentel & $\mathrm{X}$ & & $\mathrm{X}$ & $\mathrm{X}$ & $\mathrm{X}$ & & \\
\hline 1646 & Juan Antonio Velázquez & & & $\mathrm{X}$ & & $\mathrm{X}$ & & \\
\hline $1648-1659$ & Francisco Cachupin & & & $\mathrm{X}$ & & & & \\
\hline 1650 & Pedro Pimentel & $\mathrm{X}$ & & $\mathrm{X}$ & $\mathrm{X}$ & $\mathrm{X}$ & & \\
\hline $1651-1654$ & Martín de Lezaun & & & $\mathrm{X}$ & & & $\mathrm{X}$ & \\
\hline $1655-1657$ & Francisco Bergara o Vergara & & & & $\mathrm{X}$ & $\mathrm{X}$ & & \\
\hline $1658-1660$ & Miguel Arbizu & & & $\mathrm{X}$ & & & $\mathrm{X}$ & \\
\hline $1661-1663$ & Francisco Bergara o Vergara & & & & $\mathrm{X}$ & $\mathrm{X}$ & & \\
\hline $1664-1666$ & Juan Barbiano & $\mathrm{X}$ & $\mathrm{X}$ & & & $\mathrm{X}$ & & \\
\hline $1667-1668$ & $\begin{array}{l}\text { Pedro Jerónimo Fernández de } \\
\text { Córdoba }\end{array}$ & $\mathrm{X}$ & & $\mathrm{X}$ & & & $\mathrm{X}$ & \\
\hline $1669-1673$ & Diego de la Fuente Hurtado & $\mathrm{X}$ & & $\mathrm{X}$ & & & & \\
\hline $1674-1675$ & Benito Vázquez & & & $\mathrm{X}$ & & & $\mathrm{X}$ & \\
\hline $1676-1679$ & Antonio Losada & & & & $\mathrm{X}$ & & & \\
\hline 1680 & Pascual Casanova & & & $\mathrm{X}$ & & & & \\
\hline $1681-1682$ & Juan Nieto & & & $\mathrm{X}$ & & & $\mathrm{X}$ & \\
\hline $1683-1685$ & Gregorio Sarmiento & & & $\mathrm{X}$ & $\mathrm{X}$ & & & $\mathrm{X}$ \\
\hline $1686-1688$ & Antonio Losada & & & & $\mathrm{X}$ & & & \\
\hline $1689-1691$ & $\begin{array}{c}\text { Antonio Carabes o Caraveo o } \\
\text { Carabeo }\end{array}$ & & & $\mathrm{X}$ & & & & \\
\hline $1692-1694$ & Gregorio Sarmiento & & & $\mathrm{X}$ & $\mathrm{X}$ & & & $\mathrm{X}$ \\
\hline $1695-1696$ & Francisco Xavier & & $\mathrm{X}$ & $\mathrm{X}$ & $\mathrm{X}$ & & & \\
\hline $1697-1700$ & Francisco Aleson & & & & & & $\mathrm{X}$ & \\
\hline $1701-1703$ & Francisco Xavier & & $\mathrm{X}$ & $\mathrm{X}$ & $\mathrm{X}$ & & & \\
\hline $1704-1705$ & Bernardo Peñalta & & & $\mathrm{X}$ & & & & \\
\hline $1706-1708$ & Salvador Ribadeo & & & $\mathrm{X}$ & & & & \\
\hline $1709-1711$ & José Félix de Bargas o Vargas & & & $\mathrm{X}$ & $\mathrm{X}$ & & & \\
\hline $1712-1715$ & José Antonio Beaumont & & & $\mathrm{X}$ & & & $\mathrm{X}$ & \\
\hline $1716-1718$ & Nicolás Bordás & $\mathrm{X}$ & & $\mathrm{X}$ & & $\mathrm{X}$ & & \\
\hline $1719-1721$ & José Félix de Bargas o Vargas & & & $\mathrm{X}$ & $X$ & & & \\
\hline
\end{tabular}


CRISTO JOSÉ DE LEÓN PERERA

RECTORES DEL COLEGIO DE LA COMPAÑÍA DE JESÚS EN SALAMANCA: APROXIMACIÓN HISTÓRICA A UN DOMICILIO UNIVERSITARIO

\begin{tabular}{|c|c|c|c|c|c|c|c|c|}
\hline Período de rectorado & Padre rector & A & C & P & R & V & VP & H \\
\hline $1722-1724$ & Francisco Valencia & & & & & & & \\
\hline $1725-1727$ & Juan de Villafañe & & & & X & & & \\
\hline $1728-1731$ & $\begin{array}{c}\text { Alonso o Idelfonso Cifuentes o } \\
\text { Zifuentes }\end{array}$ & & & & & & \\
\hline $1732-1734$ & Francisco de Miranda & & X & X & X & & & X \\
\hline $1735-1736$ & Juan de Villafañe & & & & X & & & \\
\hline 1737 & Francisco Miranda & & X & X & X & & & X \\
\hline $1738-1739$ & Manuel de Prado & & & X & & & & \\
\hline 1740 & Andrés Ortiz de Zárate & X & & X & & & X & \\
\hline $1741-1744$ & Fernando Morales & & X & & & & & \\
\hline $1745-1747$ & Luis de Meneses & & & & & & & \\
\hline $1748-1751$ & Salvador Osorio & & X & & X & X & & X \\
\hline $1752-1754$ & Eugenio de Colmenares & & & X & & & X & \\
\hline $1755-1757$ & Clemente Recio & & & X & & X & & \\
\hline $1758-1761$ & Ignacio Osorio & & X & X & X & & & \\
\hline $1762-1763$ & $\begin{array}{c}\text { Francisco Xavier Idiáguez o } \\
\text { Idiáquez }\end{array}$ & & X & & & & X \\
\hline $1764-1767$ & Ignacio Osorio & & X & X & X & & & \\
\hline
\end{tabular}

\section{Leyenda}

\begin{tabular}{|l|l|}
\hline A & Admitido en el colegio de Salamanca \\
\hline C & Catedrático de propiedad Universidad de Salamanca \\
\hline P & Provincial \\
\hline R & Repiten en el cargo \\
\hline V & Vicerrector \\
\hline VI & Visitador provincial \\
\hline VP & Viceprovincial \\
\hline H & Asistente Hispania \\
\hline
\end{tabular}

Fuente: Elaboración propia. 
CRISTO JOSÉ DE LEÓN PERERA

RECTORES DEL COLEGIO DE LA COMPAÑÍA DE JESÚS EN SALAMANCA: APROXIMACIÓN HISTÓRICA A UN DOMICILIO UNIVERSITARIO

\section{BIBLIOGRAFÍA}

Burrieza Sánchez, J. (2000). Los años fundacionales de la Compañía de Jesús en Valladolid. Hispania Sacra, 52, 105, 139-162.

-, (2002). Las cátedras pro «religione» en la Universidad de Valladolid. Revista de historia moderna de la Universidad de Alicante, 20, 149-186.

-, (2013). Ripalda, Jerónimo de. Diccionario biográfico español. Tomo XLIII. Real Academia de la Historia, 515-516.

De León Perera, C. J. (2018a). Los jesuitas en la Salamanca de la Edad Moderna: estado de la cuestión. En: M. A. Pena e I. Delgado (coords.), Humanismo cristiano y Reforma protestante (1517-2017). Salamanca: Universidad Pontificia de Salamanca, 387-397.

-, (2018b). La Compañia de Jesús en Salamanca (1548-1767). Vida cotidiana entre la misión y la universidad. Salamanca: Centro de Estudios Salmantinos.

-, (2018c). La mujer y su importancia en uno de los centros colegiales vinculado a la Universidad (1527-1767). En: M. Martín, J. M. Martín y Ma. I. García (coord.). Mujeres dentro y fuera de la Academia. Salamanca: Aquilafuente, 110-129.

-, (2019). Miguel de Torres: la elección humanista del primer rector jesuita de Salamanca. En: M. A. Pena e I. Delgado (coords.), Humanistas, Helenistas y Hebraistas en la Europa de Carlos V. Fuentes Documentales, 12, Salamanca: Universidad Pontificia de Salamanca, 353-379.

-, (2020). La Compañía de Jesús en la Salamanca universitaria. Aspectos institucionales, socioeconómicos y culturales (1548-1767). Salamanca: Universidad de SalamancaUniversidad Pontificia Comillas.

Echarte Oñate, I. (2001). Rector. En: C. O’Neil (coords.), Diccionario bistórico de la Compañía de Jesús. Biográfico-Temático. Tomo 1. Roma-Madrid: Institutum Historicum Societatis Iesu-Universidad Pontificia Comillas, 1750.

González Dávila, G. (1606). Historia de las antigüedades de la ciudad de Salamanca: vidas de sus obispos y cosas sucedidas en su tiempo. Salamanca: Artus Taberniel.

Hernández Montes, B. (1984). La «Editio Princeps» del Ripalda se conserva en Salamanca. Boletín Oficial del Obispado de Salamanca, julio-agosto, 360-362.

Hernández Montes, B. (1987). El Colegio de la Compañía y la Universidad de Salamanca. Desde los orígenes hasta la incorporación a la Universidad. Studia Historica. Historia Moderna, 7, 723-744.

Huntington, S. (2005). El choque de civilizaciones y la reconfiguración del orden mundial. Barcelona: Paidós Ibérica.

Martínez de la Escalera, J. (2001). Barbiano, Juan. En: C. O’Neil (coords.), Diccionario histórico de la Compañia de Jesús. Biográfico-Temático. Tomo 1. Roma-Madrid: Institutum Historicum Societatis Iesu-Universidad Pontificia Comillas, 343-344.

Morán, A. (1950). El primer Catedrático jesuita de Prima de Teología en la antigua Universidad de Salamanca. Misceláneas Comillas, 14, 85-142.

O’Malley, J. (2016). ¿Santos o demonios? Estudios sobre la historia de los jesuitas. Vizcaya: Mensajero.

Ediciones Universidad de Salamanca / @@ Stud. his., H. ${ }^{a}$ mod., 42, n. 1 (2020), pp. 255-285 
CRISTO JOSÉ DE LEÓN PERERA

RECTORES DEL COLEGIO DE LA COMPAÑÍA DE JESÚS EN SALAMANCA: APROXIMACIÓN HISTÓRICA A UN DOMICILIO UNIVERSITARIO

Resines Llorente, L. (1987). Catecismos de Astete y Ripalda. Madrid: Biblioteca de Autores Cristianos.

-, (1996). Astete frente a Ripalda: dos autores para una obra. Teología y Catequesis, 89-138.

-, (2001). Jerónimo de Ripalda. En: C. O’Neil (coords.), Diccionario bistórico de la Compañia de Jesús. Biográfico-Temático. Tomo 4. Roma-Madrid: Institutum Historicum Societatis Iesu-Universidad Pontificia Comillas, 3364-3365.

Rodríguez de Ceballos, A. (1966). El primitivo Colegio de la Compañía de Jesús en Salamanca (1545-1665). Miscelanea Comillas, 46, 103-168.

Sommervogel, C. (1895). Bibliothèque de la Compagnie de Jésus. Première partie: bibliographie per les Pères Angustin et Aloya de Backer. Seconde partie: historie per le Père Auguste Carayon. Tomo 6. Bruselas-París: Société de Librairie-Libraire des Archives nationales et de l'École des Chartes, 1863-1874.

Vila Despujol, I. (2010). La Compañía de Jesús en Barcelona en el siglo XVI. El Colegio de Nuestra Señora de Belén. Roma-Madrid: Institutum Historicum Societatis IesuUniversidad Pontificia Comillas.

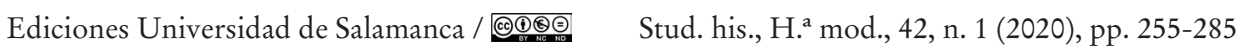

